\title{
Cluster analysis of electric energy consumption in metallurgy enterprises
}

\author{
R.V. Klyuev \\ Grand PhD in Engineering sciences, Head of Department, North-Caucasian Institute of mining and metallurgy \\ (State Technological University), Vladikavkaz, Professor, Moscow Polytechnic University, Moscow, Russia
}

\author{
I.I. Bosikov \\ PhD in Engineering sciences, Associate Professor, North-Caucasian Institute of mining and metallurgy \\ (State Technological University), Vladikavkaz, Russia
}

O.A. Gavrina

PhD in Engineering sciences, Associate Professor, North-Caucasian Institute of mining and metallurgy (State Technological University), Vladikavkaz, Russia

\begin{abstract}
To increase the efficiency of energy use at non-ferrous metallurgy enterprises, an integrated approach is required to assess energy consumption. Therefore, the urgent issue is the development of a methodology that most fully reflects the specifics of the non-ferrous metals production, based on the methods of expert evaluations, cluster and rank analysis, which allows us to evaluate and implement energy management. The objectives of the research in this work are: development of a methodology for expert assessments, which allows to assess the influence degree of technological production indicators of the hard alloys on the consumption of electricity; conducting a statistical analysis of expert assessments for a number of null hypotheses; development of a methodology for cluster analysis of the main indicators of technocenosis, which allows one to build histograms and mathematical models of the distribution of the sums of ranks of expert assessments for all castes of rank distribution. The formation of clusters and the construction of a dendrogram of weakly correlated indicators among themselves, the influence of which for individual castes on the consumption of electric energy is quantified by the values of the weighted average fuzzy numbers. Cluster analysis made it possible to clarify for the non-ferrous metallurgy enterprise significant weakly correlated indicators that have the greatest impact on electricity consumption. An analysis of significant weakly correlated indicators showed that they are all divided into two main groups on the basis of their possible use to obtain the regression equation.
\end{abstract}

\section{INTRODUCTION}

Non-ferrous metallurgy enterprises for the production of hard alloys are large consumers of electricity. The operation mode of these enterprises is determined by the specifics of technological processes. Electricity consumption is influenced by a large number of rather vague factors. Therefore, to solve the important and urgent task of increasing the efficiency of electricity use, it is necessary to first determine the factors themselves and assess the degree of their influence on electricity consumption using expert assessment methods and cluster analysis.

The use of expert assessment methods and cluster analysis in various industries is the focus of the work of Russian scientists (Beshelev \& Gurvich. 1980), (Frenkel. 1977), (Vartazarov, Gorlov, Minaev, \& Khvastunov. 1981) and foreign scientists (Bann \& Farmer. 1987), (Draper \& Smith. 1973), (Duran \& Odell. 1977), (Kendall. 1975), (Lee \& Deb. 2018), (Liao \& He. 2018), (Ioppolo, Boffardi \& Ar-bolino. 2019), (Meschede, Esparcia, Holzapfel \& Bertheau. 2019). 


\section{RESEARCH METHODS AND MATERIALS}

In present work, to solve the problem of improving the efficiency of use at non-ferrous metallurgy enterprises, a research method based on expert assessments is used. As experts, professionals in the field of carbide production at a non-ferrous metallurgy enterprise were involved.

The developed methodology for expert assessments of the influence degree of technological evaluated indicators on electricity consumption is based on the analysis of rank correlation, which allows formalizing a priori information of experts.

As experts, professionals in the field of technology of production processes, power plants and researchers associated with the production of hard alloy were involved. Due to the heterogeneity of experts, a "weight" coefficient is assigned to each of them to obtain a more objective average assessment. The proposed differentiated scale of "weight" coefficients $\beta_{j}$, taking into account the qualifications of the expert, the length of service in the specialty, is shown in Table 1.

The expert qualifications are reflected in their "weight" $\beta_{j}=(0.7 \div 1.3)$. The greatest "weight" $\left(\beta_{j}=1.3\right)$ was assigned to the chief metallurgist with a work experience of more than 40 years, and the smallest $\left(\beta_{j}=0.7\right)$ to the senior power engineer of the workshop with work experience of up to 10 years.

Initial assessments of experts were obtained on the basis of developed questionnaires evaluating the influence of technological indicators of workshops on electricity consumption on a 5-point scale (Table 2).

Based on representative expert assessments for the workshop for the recovery and sintering of molybdenum from a non-ferrous metallurgy enterprise, the following main factors were identified, presented in Table 3 (Klyuev, Bosikov \& Gavrina. 2018).

Based on expert assessments, an initial matrix of ranks and a matrix of related ranks of indicators are formed (Table 4).

Table 1. Differentiated scale of experts "weight" $\beta_{j .}$

\begin{tabular}{lllll}
\hline & \multicolumn{4}{l}{ The numerical value of the "weight" of the $j$-th expert $\beta_{j}$} \\
\cline { 2 - 5 } Expert Position & \multicolumn{4}{l}{ Work experience in the specialty } \\
\cline { 2 - 5 } & up to 10 years & 10 - 20 years & 20-30 years & 30 -40 years \\
\hline Chief Metallurgist of Plant & 1.2 & 1.3 & 1.4 & 1.5 \\
Chief Technologist of Plant & 1.1 & 1.2 & 1.3 & 1.4 \\
Chief Engineer of Plant & 1.0 & 1.1 & 1.2 & 1.3 \\
Chief Power Engineer of Plant & 0.9 & 1.0 & 1.1 & 1.2 \\
Doctor, Candidate of Technical Sciences & 0.8 & 0.9 & 1.0 & 1.1 \\
Workshop Technologist & 0.7 & 0.8 & 0.9 & 1.0 \\
Senior Power Engineer & 0.6 & 0.7 & 0.8 & 0.9 \\
\hline
\end{tabular}

Table 2. The scale of expert's numerical ratings $a_{\mathrm{i}}$ the dependence of electricity consumption $(y)$ on the performance of the workshop of a non-ferrous metallurgy enterprise $\left(x_{i}\right)$.

Experts opinion on how electricity consumption (y) depends on indica- The numerical value of the tors $x_{i}$ assessment

I'm not quite sure that energy consumption depends on $x_{i}$, maybe it depends, but very weakly

I think that power consumption depends on $x_{i}$, but it does not depend much

I think that energy consumption depends on $x_{i}$, about $50 \%$ 
Table 3. The list of indicators $\left(x_{i}\right)$ for the enterprise and assessment of their impact on electricity consumption $(y)$.

\begin{tabular}{lll}
\hline $\mathrm{x}_{\mathrm{i}}$ The list of key indicators for the enterprise & Assessment of the impact of indicators on $y$ \\
\hline & Temperature in reduction, sintering and calcining & 1 \\
$x_{1}$ furnaces & 1 \\
$x_{2}$ Hydrogen quality & 3 \\
$x_{3}$ Hydrogen consumption & 5 \\
$x_{4}$ Voltage drops & 5 \\
$x_{5}$ Thermal insulation of furnaces & 1 \\
$x_{6}$ Uniform promotion of boats in the furnace & 4 \\
$x_{7}$ Loading mass of material into the boat & 2 \\
$x_{8}$ Irregular operation of equipment &
\end{tabular}

Table 4. Matrix of related ranks of indicators for the enterprise.

\begin{tabular}{|c|c|c|c|c|c|c|c|c|c|c|c|c|c|c|}
\hline \multirow[b]{2}{*}{$x_{i}$} & \multicolumn{13}{|c|}{ The experts, $m$} & \multirow{2}{*}{$-\sum_{i=1}^{m} \sum_{j=1}^{n} a_{j i}^{(2)}$} \\
\hline & 1 & 2 & 3 & 4 & 5 & 6 & 7 & 8 & 9 & 10 & 11 & 12 & 13 & \\
\hline$x_{1}$ & 2 & 4.5 & 7.5 & 3.5 & 3.5 & 1 & 4.5 & 5.5 & 6 & 8 & 8 & 5 & 5 & 64 \\
\hline$x_{2}$ & 2 & 1.5 & 3 & 5 & 5 & 5 & 1 & 4 & 1.5 & 5.5 & 6.5 & 2 & 1.5 & 43.5 \\
\hline$x_{3}$ & 5 & 4.5 & 7.5 & 6 & 3.5 & 7.5 & 3 & 8 & 3.5 & 5.5 & 6.5 & 8 & 7 & 75.5 \\
\hline$x_{4}$ & 7 & 4.5 & 4 & 7.5 & 7 & 3 & 2 & 3 & 1.5 & 2.5 & 1 & 2 & 1.5 & 46.5 \\
\hline$x_{5}$ & 8 & 7 & 5 & 1.5 & 2 & 5 & 7 & 1.5 & 8 & 5.5 & 2.5 & 5 & 6 & 64 \\
\hline$x_{6}$ & 2 & 1.5 & 1.5 & 1.5 & 1 & 2 & 7 & 1.5 & 6 & 1 & 2.5 & 2 & 3 & 32.5 \\
\hline$x_{7}$ & 6 & 8 & 6 & 3.5 & 7 & 5 & 7 & 7 & 3.5 & 2.5 & 4 & 7 & 8 & 74.5 \\
\hline$x_{8}$ & 4 & 4.5 & 1.5 & 7.5 & 7 & 7.5 & 4.5 & 5.5 & 6 & 5.5 & 5 & 5 & 4 & 67.5 \\
\hline$\sum_{j=1}^{m} \sum_{i=1}^{n} a_{j i}^{(2) \leftarrow}$ & 36 & 36 & 36 & 36 & 36 & 36 & 36 & 36 & 36 & 36 & 36 & 36 & 36 & 468 \\
\hline
\end{tabular}

\section{EXPERT ASSESSMENT METHODOLOGY}

By sequentially checking a series of null hypotheses, a fairly high qualification and consistency of expert opinions on the formation of the initial matrix and matrix of related ranks were statistically confirmed.

Based on the statistical analysis of rank correlation, a priori information on the estimated indicators was formalized. To assess the significance of the influence of individual indicators on electricity consumption, a cluster analysis of expert assessments was used.

Cluster analysis is carried out according to an algorithm corresponding to two qualitative levels: distribution of sums of ranks of expert assessments; matrix of distances between expert assessments.

The distribution of the ranks sums of expert assessments allows one to preliminarily divide the indicators by their impact on electricity consumption into significant and insignificant.

Calculation algorithm (Klyuev, Bosikov, Gavrina \& Revazov. 2018).

Median of the distribution polygon of weighted averaged averaged fuzzy numbers of indicators:

$$
m_{0}=\frac{1}{2}\left(\operatorname{maxa}_{l}+\operatorname{mina}_{l}\right)
$$

where $l=1, n ; n=$ number of indicators; $n=11$.

Weighted average of the fuzzy number for the $i$-th indicator, taking into account the "weight" of experts: 
Table 5. The calculated values of the weighted average fuzzy numbers for the indicators of the enterprise.

\begin{tabular}{|c|c|c|c|c|c|c|c|c|}
\hline \multirow[b]{2}{*}{ Designation } & \multicolumn{8}{|l|}{$\underline{x_{i}}$} \\
\hline & $x_{1}$ & $x_{2}$ & $x_{3}$ & $x_{4}$ & $x_{5}$ & $x_{6}$ & $x_{7}$ & $x_{8}$ \\
\hline$A_{i}$ & 5.0 & 3.62 & 6.31 & 3.92 & 5.00 & 2.46 & 6.38 & 5.31 \\
\hline$A_{\beta i}$ & 4.89 & 3.64 & 6.41 & 3.76 & 4.95 & 2.26 & 6.43 & 5.15 \\
\hline$A_{i^{*}}$ & 1.05 & 0.76 & 1.33 & 0.83 & 1.05 & 0.52 & 1.34 & 1.12 \\
\hline$A_{\beta i^{*}}$ & 1.13 & 0.84 & 1.47 & 0.86 & 1.14 & 0.52 & 1.48 & 1.18 \\
\hline
\end{tabular}

$$
\bar{A}_{\beta i}=\sum_{l=1}^{n} a_{l} w_{i}\left(a_{l}\right)
$$

where $w_{i}\left(a_{l}\right)=$ frequency; $\beta_{i}\left(a_{l}\right)=$ "weight" of the $j$-th expert who gave his expert assessment; $a_{l}\left(\beta_{j}\left(a_{l}\right)=(0,7 \div 1,3) ; m=\right.$ number of experts; $m=12$.

$$
w_{i}\left(a_{l}\right)=\frac{\sum_{j=1}^{m} \beta_{j}\left(a_{l}\right)}{\sum_{j=1}^{m} \beta_{j}}
$$

In relative units:

$$
\bar{A}_{\beta i *}=\frac{\bar{A}_{\beta i}}{m_{0}^{\prime}}
$$

where $m_{0^{\prime}}=$ the median value taking into account the "weight" of experts:

$$
m_{0}^{\prime}=\frac{1}{2}\left(\max \bar{A}_{\beta_{i}}+\min \bar{A}_{\beta i}\right)
$$

The results of calculating the weighted averaged fuzzy numbers are given in Table 5 .

A histogram of the distribution of the ranks sums of indicators is constructed with a preliminary determination of the relative values of the ranked sum of ranks $\Delta_{i} *$ :

$$
\Delta_{i *}=\frac{1}{m_{01}} \sum_{j=1}^{m} a_{j i}
$$

where $m_{01}=$ median of the sum of the ranks of all indicators:

$$
m_{01}=\frac{1}{2}\left(\max \sum_{j=1}^{m} a_{j i}+\min \sum_{j=1}^{m} a_{j i}\right)
$$

\section{CLUSTER ANALYSIS OF INDICATORS AFFECTING ELECTRICITY CONSUMPTION}

Figure 1 Shows a histogram of the distribution of the ranks sums and the dependence of the enterprise approximating it using the least squares method. 


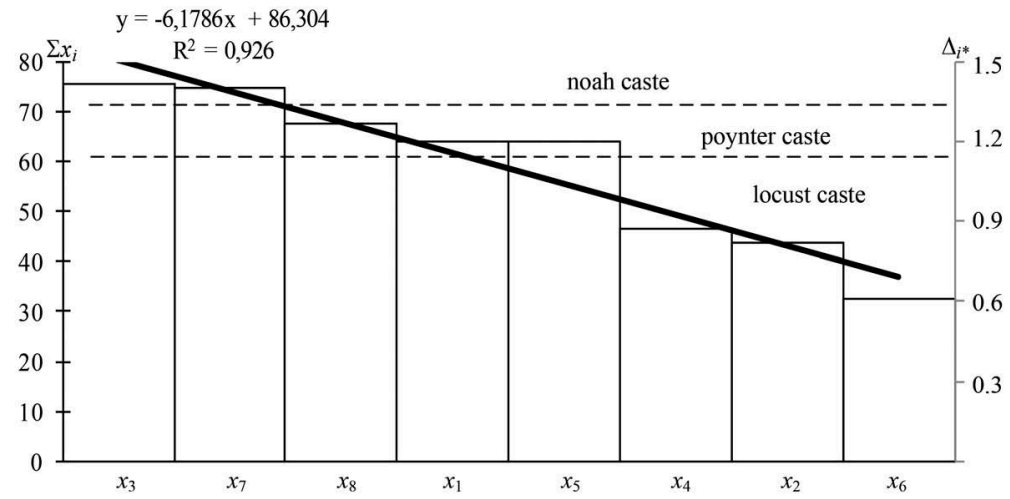

Figure 1. A histogram of the distribution of the ranks sums of expert ratings of indicators for the enterprise.

To determine the degree of proximity (correlation) between the indicators, a cluster analysis is carried out. Cluster formation is based on a matrix of distances between grouped indicators, each of which at the beginning is considered as a separate cluster (Zaalishvili, Kanukov, Melkov, Makiev \& Dzobelova. 2018).

Calculation algorithm.

The degree of proximity of the indicators, calculated as the Euclidean distance between them:

$$
d_{k l}^{2}=\frac{n\left(n^{2}-1\right)}{6}\left(1-r_{k l}^{2}\right)
$$

where $k, l=$ considered indicators; $k \neq l$.

Sample pair correlation coefficient:

$$
r_{k l}=\frac{\frac{\left[\sum_{j=1}^{m}\left(a_{j k} a_{j l}\right)\right]}{m-1}-a_{k} a_{l}\left(\frac{m}{m-1}\right)}{\bar{s}_{k} \bar{s}_{l}}
$$

where $a_{k}, a_{l}=$ sample averages of indicators $k, l$; standards of indicators $k, l$ :

$$
\begin{aligned}
& \bar{s}_{k}^{2}=\frac{1}{m-1} \sum_{j=1}^{m}\left(a_{j k}-\bar{a}_{k}\right)^{2} \\
& \bar{s}_{l}^{2}=\frac{1}{m-1} \sum_{j=1}^{m}\left(a_{j l}-\bar{a}_{l}\right)^{2}
\end{aligned}
$$

The process of cluster formation ends when all indicators are combined, which will happen in the last step of the unification.

Based on the calculation results, a divisible tree of hierarchical classification of indicators and the corresponding dendrogram of indicator clusters, shown in Figure 2 and Figure 3 are drawn. 


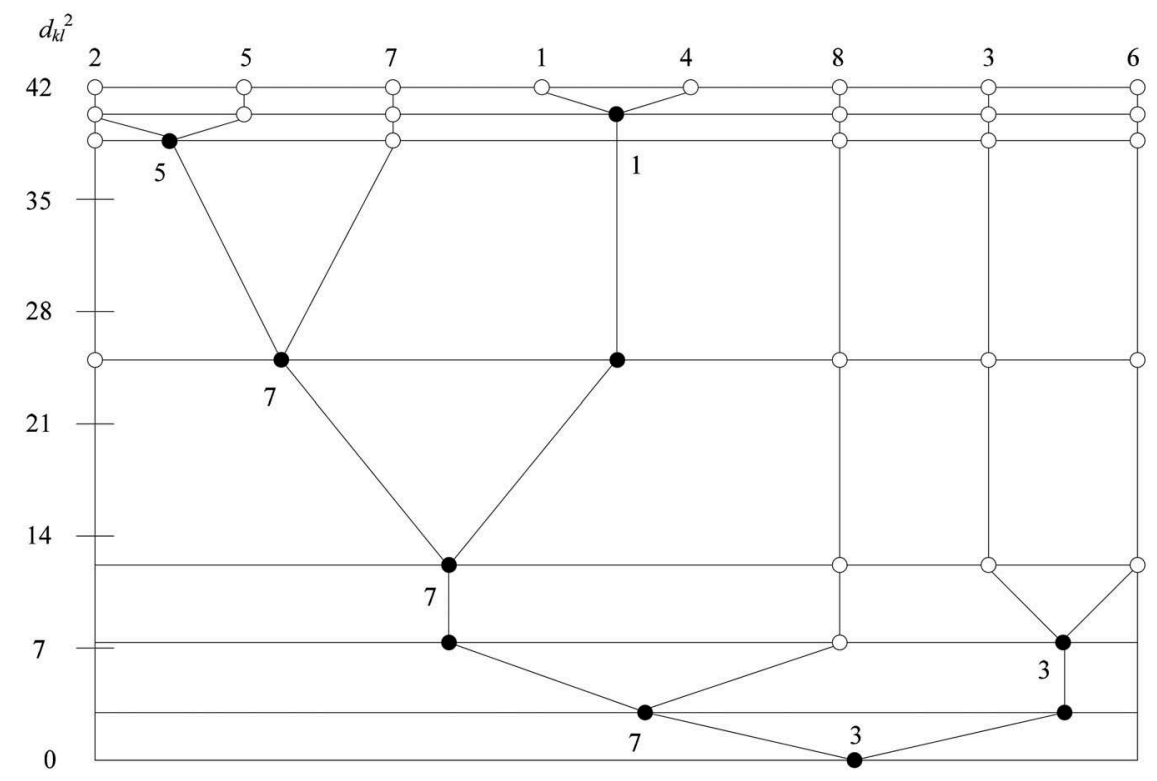

Figure 2. Divisible tree of hierarchical classification of enterprise indicators.

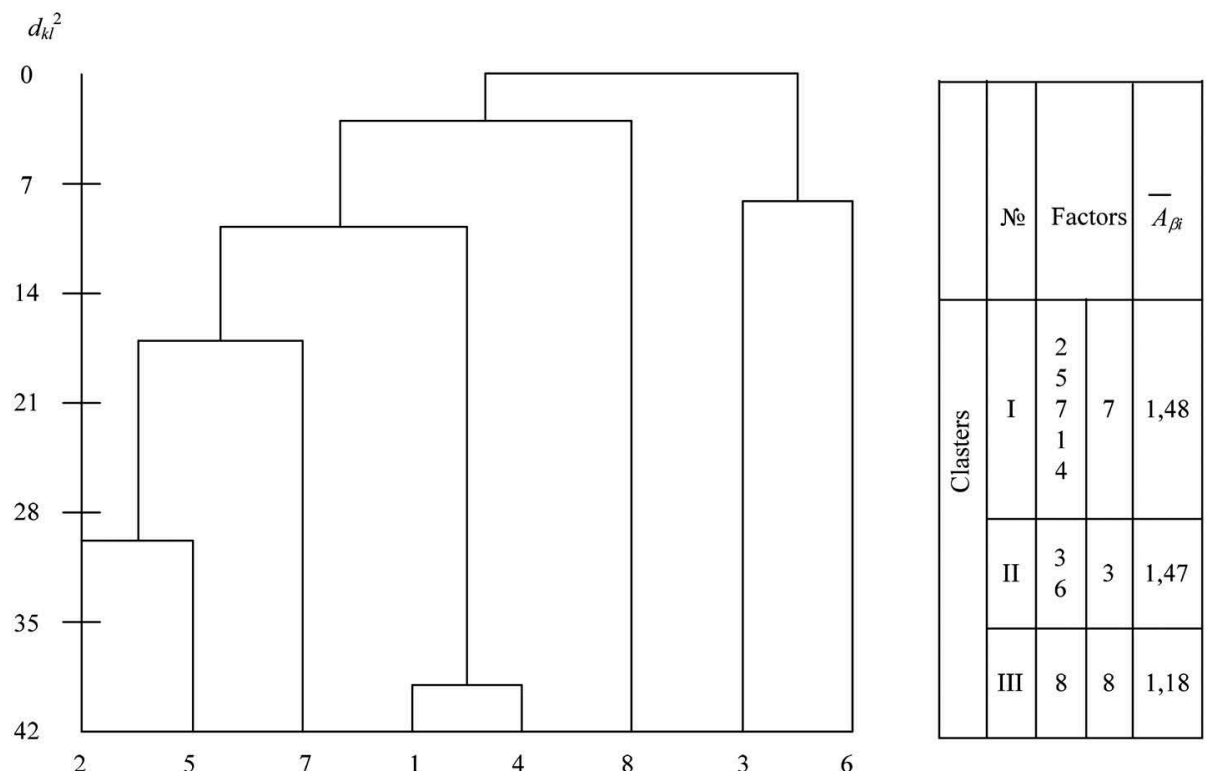

Figure 3. Dendrogram clusters of enterprise indicators.

\section{CLUSTER ANALYSIS RESULTS}

The cluster analysis made it possible to clarify significant weakly correlated indicators among the workshop of the enterprise that have the greatest impact on electricity consumption (Shempelev, Zaalishvili \& Kukhmazov. 2017). The list of indicators included in Noah, Pointer, Locust distribution castes and the values of weighted average fuzzy numbers are shown in Table 6. 
Table 6. List of indicators divided by distribution castes.

\begin{tabular}{llll}
\hline & & \multicolumn{2}{l}{ Designation } \\
\cline { 3 - 4 } № & Name of indicator & $x_{i}$ & $A_{\beta i^{*}}$ \\
\hline Noah distribution caste & $x_{3}$ & 1.47 \\
1 & Hydrogen consumption & $x_{7}$ & 1.48 \\
2 & Loading mass of material into the boat & $x_{8}$ & 1.18 \\
Poynter caste distribution & $x_{5}$ & 1.14 \\
1 & Irregular operation of equipment & $x_{1}$ & 1.13 \\
2 & Thermal insulation of furnaces & & \\
3 & Temperature in reduction, sintering and calcining furnaces & $x_{4}$ & 0.86 \\
Locust distribution caste & $x_{2}$ & 0.84 \\
1 & Voltage drops & $x_{6}$ & 0.52 \\
2 & Hydrogen quality &
\end{tabular}

An analysis of significant indicators that are weakly correlated with each other showed that they are all divided into two main groups based on their possible use to obtain a regression equation of the form $y=f\left(x_{i}\right)$.

The first group includes indicators that make it possible to quantify them directly or indirectly (points 1, 2 (Noah caste), point 3 (Pointer caste), points 1, 3 (Locust caste)).

The second group includes indicators that are difficult (points 1, 2 (Pointer caste), or non formalized point 2 (Locust caste).

Increasing material interest and improving working conditions will increase the level of repair and maintenance of equipment and have a significant impact on reducing losses and specific electricity consumption (Eraky, M.T., Zubov, D.V. \& Krysanov K.S. 2019).

\section{MATHEMATICAL MODEL OF SPECIFIC POWER CONSUMPTION OF METALLURGICAL PRODUCTION FURNACES BASED ON A FULL FACTORIAL EXPERIMENT}

Mathematical models of the dependence of the specific energy consumption on technological factors were obtained during a full factorial experiment (PFE). On resistance furnaces, PFE of the form $N=2^{2}$ was carried out using two technological factors $\left(x_{1}, x_{2}\right)$ at two levels of variation.

The algorithm for obtaining a mathematical model based on PFE is given below.

1. According to the current technological control of the studied factors, the conditions for conducting experiments in natural and code scales are determined.

2. A planning matrix for PFE is compiled, which presents the results of the experiments. To calculate the variances of the output parameter (specific energy consumption) and to verify their homogeneity, parallel experiments are performed with the number $m$.

3. The hypothesis $\mathrm{H} 0$ is tested: at the accepted significance level $\alpha=0,05$, the variances are homogeneous. The homogeneity of the dispersions is checked by the Cochren criterion $G_{\max }$. The tabulated critical value of the Cochren criterion $G\left(f_{1}, f_{2}\right)$ is determined at values $f_{1}=m-1 ; f_{2}=N$ and $\alpha=0,05$.

4. The coefficients of the regression equation are determined from the PFE planning matrix.

5. The significance of the coefficients of the regression equation is estimated based on the method of regression analysis using the calculated values of the Student t-test. Significant are the coefficients for which the condition $t_{i j}>t_{m}\left(f_{1}, \alpha\right)$ is satisfied.

6. The adequacy of the obtained regression equation is checked by the variance values - the average of the PFE and the residual - regression equation. The regression equation adequately describes the process under study if the condition $>$ is satisfied. 
Table 7. Test conditions in natural and code scales.

\begin{tabular}{|c|c|c|c|c|c|c|}
\hline \multirow[b]{2}{*}{ № } & \multirow[b]{2}{*}{ Factors } & & \multicolumn{4}{|c|}{ Levels and interval of variation of factors } \\
\hline & & & lower & upper & main & interval \\
\hline 1 & $x_{1}$ & $\gamma, \mathrm{kg}$ & 110 & 130 & 120 & 10 \\
\hline \multirow[t]{2}{*}{2} & $x_{2}$ & $V, \mathrm{~m}^{3}$ & 8 & 10 & 9 & 1 \\
\hline & & & -1 & 1 & 0 & $\Delta i$ \\
\hline
\end{tabular}

Table 8. PFE planning matrix $N=2^{2}$ and experimental results.

\begin{tabular}{|c|c|c|c|c|c|c|c|c|c|}
\hline \multirow[b]{2}{*}{ № } & \multicolumn{3}{|c|}{ Code scale } & \multicolumn{2}{|c|}{ Natural scale } & \multicolumn{3}{|c|}{$W_{\text {specific }}, \mathrm{kWh} / \mathrm{kg}(y)$} & \multirow[b]{2}{*}{$W_{\text {specific.average }}, \mathrm{kWh} / \mathrm{kg}$} \\
\hline & $x_{0}$ & $x_{1}$ & $x_{2}$ & $\gamma, \mathrm{kg}$ & $V, \mathrm{~m}^{3}$ & 1 & 2 & 3 & \\
\hline 1 & 1 & -1 & -1 & 110 & 8 & 0.91 & 0.95 & 0.86 & 0.91 \\
\hline 2 & 1 & 1 & -1 & 130 & 8 & 0.78 & 0.81 & 0.74 & 0.78 \\
\hline 3 & 1 & -1 & 1 & 110 & 10 & 1 & 1.05 & 0.98 & 1.01 \\
\hline 4 & 1 & 1 & 1 & 130 & 10 & 0.84 & 0.87 & 0.83 & 0.85 \\
\hline$\Sigma$ & & 0 & 0 & & & & & & 3.55 \\
\hline
\end{tabular}

7. A transition is made from the code values of independent variables to their values in physical units.

To conduct PFE as technological factors that have the most significant effect on the specific energy consumption, the following were determined: $x_{1}$ - mass of ammonium paramolybdate loaded into the furnace, $\gamma, \mathrm{kg} ; x_{2}$ is the amount of hydrogen, $V, \mathrm{~m}^{3}$.

In the Table 7 shows the conditions for conducting PFE experiments in natural and code scales, in Table 8 - PFE planning matrix and experimental results.

According to the condition $t_{i j}>t_{m}\left(f_{1}, \alpha\right)$, the coefficients $\mathrm{b}_{1}$ and $\mathrm{b}_{1}$ are significant. In this case, the regression equation has the form:

$$
\mathrm{y}=88.75 \cdot 10-^{2} \cdot-\cdot 7.25 \cdot 10-^{2} x_{1} \cdot+\cdot 4.25 \cdot 10-^{2} x_{2}
$$

Moving from the code values of independent variables to their values in physical units, we obtain a mathematical model:

$$
W_{\text {specific }}=1.375-7.25 \cdot 10-{ }^{3} \gamma+4.25 \cdot 10-{ }^{2} V, \mathrm{kWh} / \mathrm{kg}
$$

\section{CONCLUSION}

1. An analysis of the histograms of the distribution of the ranks sums of the expert assessments of technological indicators made it possible to select a cluster of significant $(\Delta i *>1)$ indicators and group them according to the degree of influence on energy consumption.

2. The analysis of dendrograms showed that the considered totality of indicators for the workshop of the non-ferrous metallurgy enterprise forms 3 clusters with the values of the weighted average fuzzy number for the $i$-th indicator taking into account the "weight" of experts within $(0.52 \div 1.48)$.

3 . Based on the cluster analysis, statistically significant slightly correlated indicators were specified that have the greatest impact on electricity consumption (Table 6). 
4. The objective of further research is to determine the type of functional of the equation $y=f\left(x_{i}\right)$ and to optimize electricity consumption for a complex of non-ferrous metallurgy enterprises.

5. The results obtained in the work can be used at industrial enterprises of various industries. Of particular relevance are the results when it is impossible to carry out instrumental measurements of the parameters of electricity consumption and the values of technological indicators.

\section{REFERENCES}

Beshelev, S.D. \& Gurvich F.G. 1980. Mathematical and statistical methods of expert estimates. Moscow. Statistics.

Bann, D.V. \& Farmer, E.D. 1987. Comparison models of electric load forecast. Moscow. Energoatomizdat.

Draper, N. \& Smith, H. 1973. Applied regression analysis. Moscow. Mir.

Duran B. \& Odell, P. 1977. Cluster analysis. Moscow. Statistics.

Frenkel, A.A. 1977. Analysis of factors of growth of labor productivity using expert assessments. Moscow. Nauka.

Kendall, M. 1975. Rank correlations. Foreign statistical studies. Moscow. Statistics.

Klyuev, R.V., Bosikov, I.I. \& Gavrina, O.A. 2018. Development of Mathematical Model for Specific Power Consumption of Resistance Furnaces at Non-Ferrous Metallurgy Enterprises. International Russian Automation Conference (RusAutoCon), Sochi, 9-16 September 2018. IEEE.

Klyuev, R.V., Bosikov, I.I., Gavrina, O.A., \& Revazov, V.Ch. 2018. System analysis of power consumption by nonferrous metallurgy enterprises on the basis of rank modeling of individual technocenosis castes. MATEC Web Conf. 226. (2018) 04018. EDP Sciences.

Lee, S. \& Deb, Ch. 2018. Determining key variables influencing energy consumption in office buildings through cluster analysis of pre- and post-retrofit building data. Energy and Buildings 159: 228-245.

Liao, N. \& He, Y. 2018. Exploring the effects of influencing factors on energy efficiency in industrial sector using cluster analysis and panel regression model. Energy 158: 782-795.

Ioppolo, G., Boffardi, R. \& Arbolino, R. 2019. The effectiveness of European energy policy on the Italian system: Regional evidences from a hierarchical cluster analysis approach. Energy Policy 132: 47-61.

Meschede, H., Esparcia, E., Holzapfel, P. \& Bertheau, P. 2019. On the transferability of smart energy systems on off-grid islands using cluster analysis - A case study for the Philippine archipelago. Applied Energy 251. Article 113290.

Shempelev, A.G., Zaalishvili, V.B. \& Kukhmazov, S.U. 2017. Deep structure of the western part of the Central Caucasus from geophysical data. Geotectonics, 51(5): pp. 479-488.

Vartazarov, I.S., Gorlov, I.G., Minaev, E.V., \& Khvastunov, R.M. 1981. Expert assessments and their application in the energy sector. Moscow. Energoizdat.

Zaalishvili, V.B., Kanukov, A.S., Melkov, D.A., Makiev, V.D. \& Dzobelova, L.V. 2018. Development of a unified model of geoinformation system for city planning and integration. International Journal of GEOMATE, 15(51): pp. 160-166.

Eraky, M.T., Zubov, D.V. \& Krysanov K.S. 2019. Manipulator Robot Using a New Developed Geometrical Approach Method for Improvement of Quality Food and Chemical Industries. International Journal of Engineering Research and Technology, 12: 1423-1430. 